\title{
Do airport hotels continue to be a growth opportunity, and which airports present the best opportunities?
}

Received: 6 April 2004

Joni Smith

works with CB Richard Ellis Hotels' teams across Europe, the USA and the Asia Pacific region on transactions and advisory projects. Her role includes assisting the senior team in investment disposal and acquisitions, operator selection and development consultancy.

Prior to joining CBRE Hotels' team in London, Joni was a consultant with KPMG'S Travel, Leisure and Tourism team, specialising in advisory projects for hotels and hospitality companies. She previously held various management positions in hospitality companies and attended the University of Surrey to study for her BSc (Hons) Degree in Hotel and Catering Management where she was a Möet et Chandon Scholarship prizewinner.

\begin{abstract}
The hotel industry is inextricably linked to the transport industry and this link is most obvious at transport hubs. Indeed, the origins of the modern hotel industry across Europe came initially from the growth of the rail industry. Air travel has made it possible to reach across the globe and this has established the development of substantial hotel markets serving airports and their many millions of passengers each year. This paper explores the opportunity for the development of hotels at airports and the critical success factors in such hotels. The European hotel market has faced a number of issues as a result of world events and this paper comments on the impact of these events on both air travel and airport hotel performance. This includes an assessment of the dependence of hotels on their airports to generate demand. Research in this paper also illustrates how a direct link to an airport terminal can generate significant premiums in average rate and increased occupancy rates. Finally, the paper covers the outlook for airport hotels in the future and the opportunities and threats from new products and services.
\end{abstract}

\section{Keywords:}

airport hotels, airline industry terminal links, growth, opportunity, connectivity

\section{INTRODUCTION}

The hotel industry is inextricably linked to the transport industry, and this link is most obvious at transport hubs. Indeed, the origins 
Major European airports

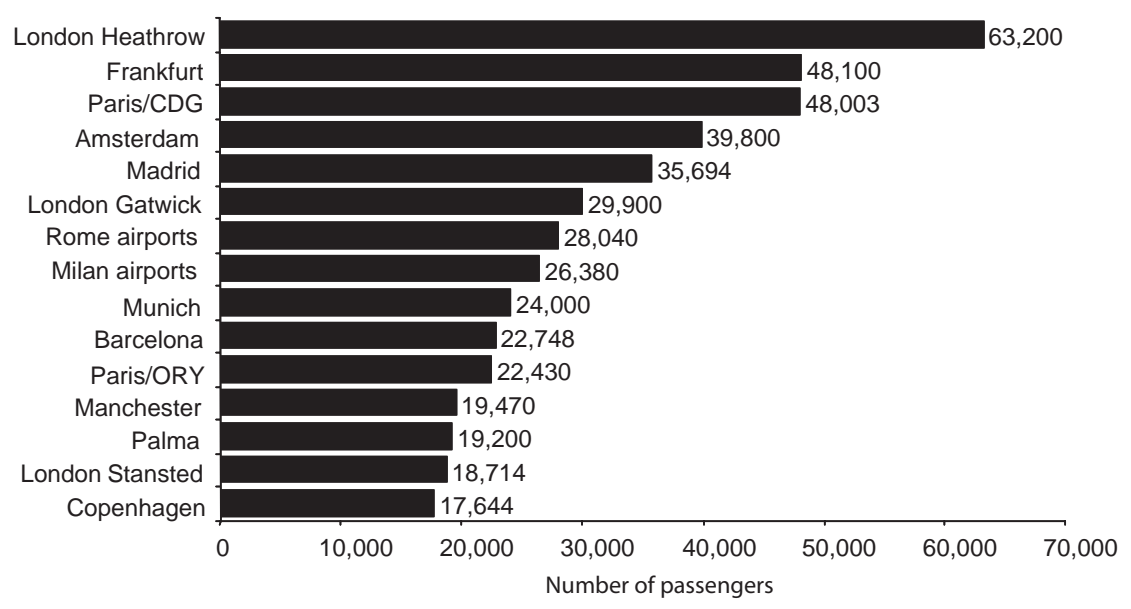

Figure 1: Europe's largest airports, 2003

Source: $\mathrm{ACl}$

of the modern hotel industry across Europe came initially from the growth of the rail industry, with some of the most venerable hotels built to serve the needs of travellers by rail.

Air travel has allowed people to reach across the globe, and this has established the development of substantial hotel markets serving airports and their many millions of passengers each year. Furthermore, a number of the industry's largest hotel brands and companies were founded by airlines, including InterContinental Hotels, founded by Pan Am, Le Meridien by Air France and Rezidor SAS owned, of course, by SAS (Scandinavian Airlines).

\section{THE GROWTH OF AIR TRAVEL}

One of the major reasons for this link between air travel and hotels is the significant rate of growth of air travel. Taking the British Airport Authority's (BAA's) figures since 1993, their seven UK airports have experienced a compound average growth rate of 5 per cent per annum by number of passengers. In 1993 these airports served just under 81 million passengers, which had increased to over 131 million by 2003 .

Figure 1 illustrates the numbers of passengers at Europe's 15 largest airports. London Heathrow is clearly the leading international airport in Europe and probably in the world. Although it is third largest in the world by total number of passengers served, the top two airports (Atlanta, with around 77 million passengers, and Chicago, with over 66 million) both serve a significant domestic/national market. As such, Heathrow is arguably the world's pre-eminent international airport.

Needless to say, Heathrow has led the way in the development of airport hotel markets, and by the end of 2004 will have over 8,000 branded and quality hotel bedrooms serving its 63 million passengers each year. This makes it the UK's second largest hotel market after central London.

Similarly, Paris Charles de Gaulle, Europe's third-largest airport, 


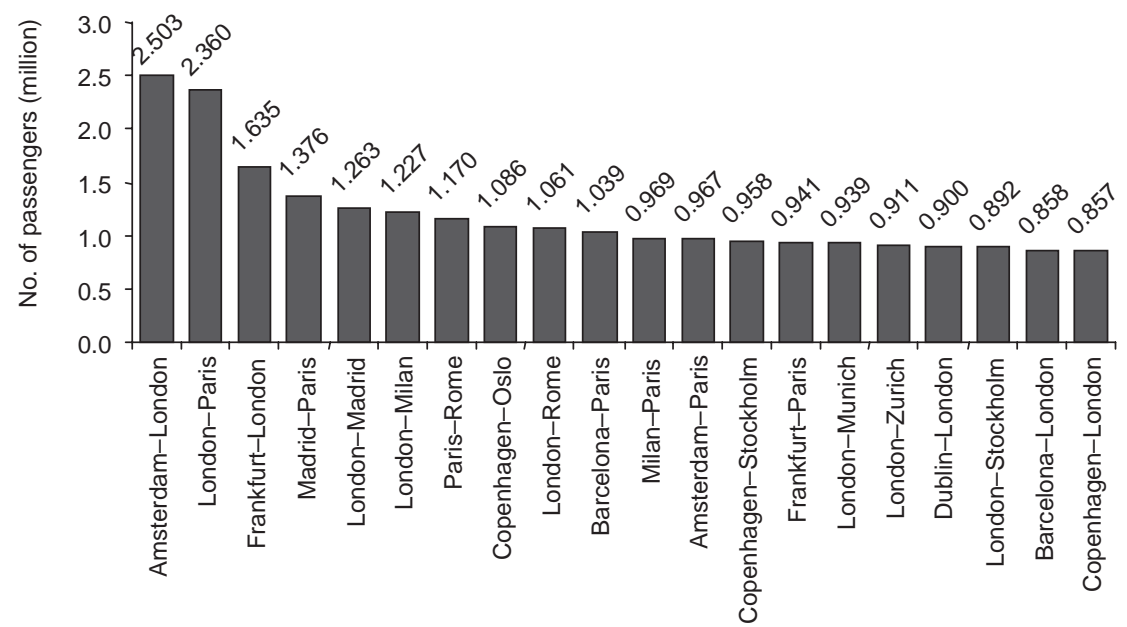

Figure 2: Top 20 city pairs, 2002 (by passenger numbers, out and back)

Source: Association of European Airlines

is served by around 3,700 hotel bedrooms and Amsterdam Schiphol has over 2,000 hotel bedrooms locally.

The link between these two industries is clear. But airports do not necessarily provide a carte blanche for hotel development across the board. There is a broad range of quality, standards and facilities provided even at Europe's busiest airports. So what factors influence the success of airport hotels?

\section{CRITICAL SUCCESS FACTORS}

Without focusing too much on London and the UK, Heathrow provides some clear examples of success factors in airport hotels. Heathrow's flights are almost entirely scheduled, a significant proportion of flights are long haul, the airport is a major hub for transit passengers and, as the primary home of the national flag carrier, a strong proportion of passengers are travelling for business purposes.

Figure 2 illustrates the most travelled routes between major European cities by number of passengers, tracked by the Association of European Airlines, which includes the major European flag carriers. A large proportion of these trips are business oriented.

At the time of the millennium, this model was probably perfect for the hotel market. But how true is this four years on, after $9 / 11$ and particularly now Heathrow is widely believed to be a major terrorist target?

The events of the past three years - including the spread of

Impact of global events
SARS and the now heightened terrorist threat - have all conspired to reduce international travel. In particular, these events have had a most significant impact on the number of transatlantic air passengers arriving in Europe. Since 2000 the number of North Atlantic passengers to BAA's UK airports has fallen by 12.5 per cent, although an 11 per cent fall occurred in the last quarter of 2001. At this stage the number of US visitors to Europe does not 


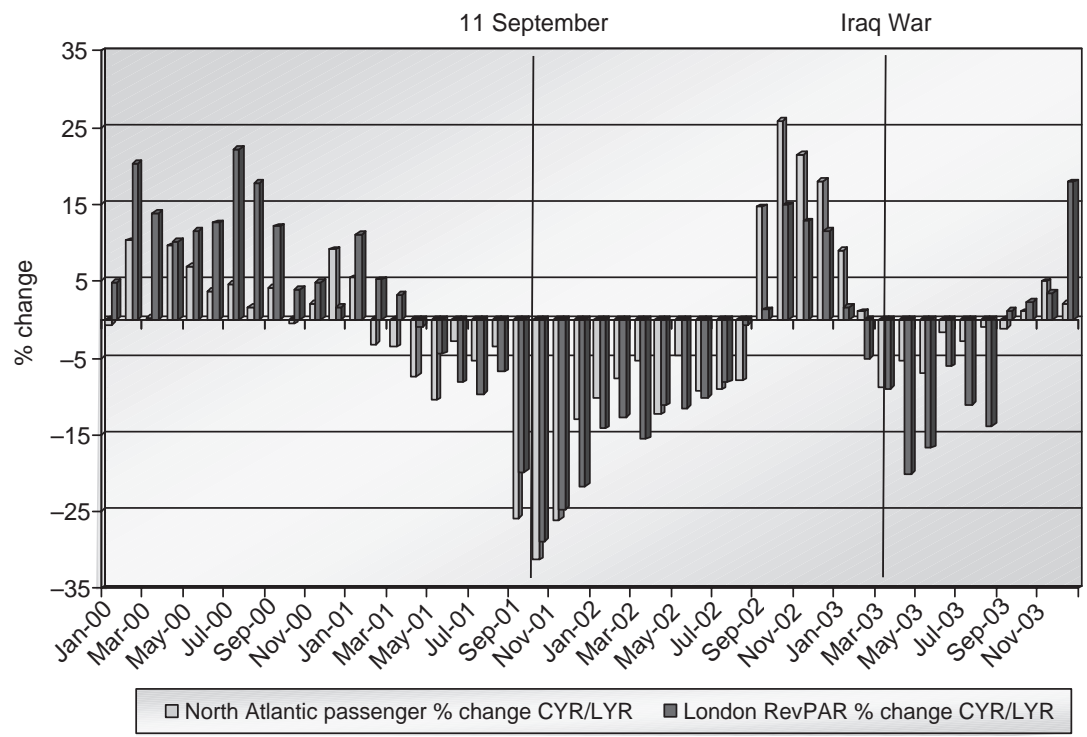

Figure 3: Correlation between changes in North Atlantic air passengers and RevPAR in the chain-operated London hotel market

Source: TRI Hospitality Consulting

appear to be bouncing back to previous levels. US visitors are also the most valuable travellers and are most likely to use branded hotel accommodation. This has had a major impact across the hotel industry's gateway cities. TRI Hospitality Consulting has produced an analysis showing the clear correlation between the number of transatlantic passengers and RevPAR in London hotels, illustrated in Figure 3.

The figure illustrates the importance of US visitors to the London hotel market as a whole, and the impact that major political events can have. It is also important to note, however, that historic evidence about the growth of air travel indicates that these events lead to only short-term declines in international travel and that the market bounces back relatively quickly. Forecasts from AEA looking at Europe's major airlines already show the expectation that air travel will grow by up to 7.5 per cent over 2004 compared with last year.

A second recent change in the airline industry is the development of secondary city airports populated by low-cost/no-frills carriers. Will these airlines have an impact on the growth of major city airports? In the light of economic uncertainty there has been pressure on businesses to cut business travel costs and use cheaper transport options where possible. Low-cost carriers have jumped in to benefit from this trend and specifically target business travellers. London Stansted is an excellent example of this model, as the airport is dominated by two of the largest low-cost airlines, Ryanair and Easyjet. Stansted has grown at a massive 22 per cent per annum on average since 1993 . But this appears to be a completely new market which has been created by these new airlines, and it has 


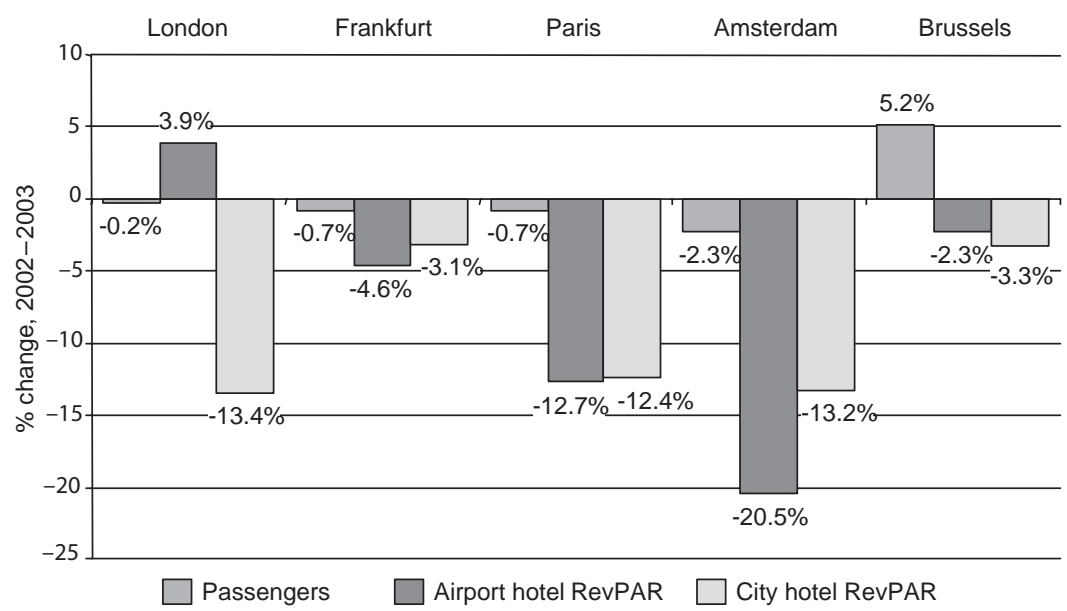

Source: ACI, Deloitte European Airport v City competitive sets, 2004

Figure 4: Passenger numbers versus RevPAR, \% change 2002-2003

not been eroding market share of the flag carriers and other major airlines. This is good news for the hotel market, evidenced by the development of two new hotels at Stansted: the Radisson SAS, which has just opened, and the Express by Holiday Inn, due to open in early 2005.

\section{HOW RELIANT ARE AIRPORT HOTELS ON THEIR AIRPORTS?}

Airports clearly represent significant opportunities for hotels; the industry has tremendous growth prospects and is a major demand generator for hotels. But are airport hotels too dependent on one market? Are all their eggs in one basket?

Figure 4 compares the change in passenger numbers between 2002 and 2003 with the change in revenue per available room (RevPAR) in a competitive set of city hotels and airport hotels over the same period. Although this is not a large sample there are some clear trends.

In Frankfurt, Paris and Amsterdam a decline in passenger numbers at the airport appears to be reflected in a fall in RevPAR in the airports' hotels which is more significant than the fall in the corresponding city hotels. This backs up the fact that, while general market forces will impact on hotel performance across the board, the airport is, of course, a major demand generator for the local hotels.

\section{Sensitivity to airport growth}

In Brussels the increasing passenger numbers were not reflected in hotel RevPAR, although it is interesting to note that occupancy in airport hotels increased and the fall in RevPAR was driven by average achieved rate. In the competitive set used, although occupancy in the airport hotels is actually lower than in the city hotels, the airport properties achieve a significant premium in average rate. In this case, the buoyant airport helped the airport hotels to outperform the city hotels. 
Effect of location on RevPAR and premium
In all four cities studied above it may be surmised that the airport hotel market is sensitive to the airport's growth. But this is also a positive, since it is believed that there is still significant room for future growth in the European air travel industry. The major threat to business is, therefore, new supply.

Heathrow Airport hotels appear to be far more buoyant than both their city equivalents and the airport itself. An increase in RevPAR of 3.9 per cent between 2002 and 2003 was driven almost entirely by increasing average rate. This result is an indication of how Heathrow has created a commercial centre in its own right, which is less reliant on pure airport business. The strength of the airport also allows hotel development to lead the way in other commercial development. The Jurys Inn at Hatton Cross is currently under construction, with around 360 bedrooms and due to open in spring 2005. The remainder of the Hatton Cross business park will be developed subsequent to the opening of the hotel.

The dependence of a hotel on the airport it serves is in part affected by the maturity of the airport itself. Gateway airports can attract a significant amount of non-airport development, including business parks and corporate headquarters, which effectively create commercial centres outside the city.

Furthermore, airport hotels lend themselves to significant conference and banqueting space since there may be fewer restrictions on space than in city centres, and hotels tend to be larger. The attractiveness of a well-connected airport hotel for an international conference can be a significant advantage. The Sheraton Frankfurt Hotel \& Towers has over 1,000 bedrooms and a major conference centre attached. Similarly, the Sheraton Amsterdam Airport Hotel and Conference Centre is a major conference and banqueting venue with 408 bedrooms. Both these properties also have the benefit of being directly linked to their respective airport terminals.

\section{WHAT DIFFERENCE DOES A TERMINAL LINK MAKE?}

Many of Europe's airports do not have the benefit of a significant commercial centre and may operate in a competitive market which is highly reliant on the airport for business. Conversely, some airports are so well connected to the city centre that airport hotels compete directly with city-centre hotels. So, what competitive advantage can airport hotels use? It can be shown that a hotel with a direct link to the airport terminal has an obvious competitive advantage and the performance of these hotels bears witness to the value of this link.

Heathrow has one terminal-linked hotel - the Hilton at Terminal 4 with 400 bedrooms. The position of the hotel adjacent to the terminal allows it to benefit from more than 100 per cent occupancy due to 'day lets' as well as overnight lets. Over the past three years it has achieved occupancy levels in excess of 95 per cent per annum - between 10 per cent and 15 per cent ahead of its 


\section{Opportunity for terminal hotels}

competitive set. Furthermore, the hotel can also achieve an average rate premium of between 25 per cent and 50 per cent above its competitors. In a market which has suffered over the past few years, the terminal hotel has maintained both rate and occupancy, showing remarkably resilient performance.

The premium achieved by terminal-linked hotels is evident in other European airport hotels. In Paris, the Sheraton at Charles de Gaulle achieves a premium in average rate of between 80 per cent and 95 per cent compared with its competitive set, although it does not achieve the high occupancies reported at the Heathrow Terminal 4 hotel. The Sheraton Frankfurt Airport similarly achieves an average rate premium of between 40 per cent and 45 per cent, albeit occupancy is substantially lower. The Sheraton Amsterdam at Schiphol also achieves a premium of around 45-50 per cent in excess of its competitors. Overall, RevPAR at an airport's terminal hotel can typically be 40 per cent higher than competitors at the airport. Terminal hotels also appear to be the first to fill and the last to empty in a turbulent market.

Despite the significant premium in average rate achieved compared with non-terminal airport hotels, the split of rooms revenue and other revenues does not appear to vary between terminal and non-terminal hotels. This suggests that other departments, including food and beverage, will also be more profitable in terminal hotels.

Terminal hotels are clearly a market in their own right. Figure 5 is intended to identify the potential opportunity for hotel development at some of Europe's major airports. This illustrates the size of the airport (number of passengers, along the $x$ axis); the size of the total airport hotel market (number of rooms, on the $y$ axis); and the bubble size indicates the total number of passengers,

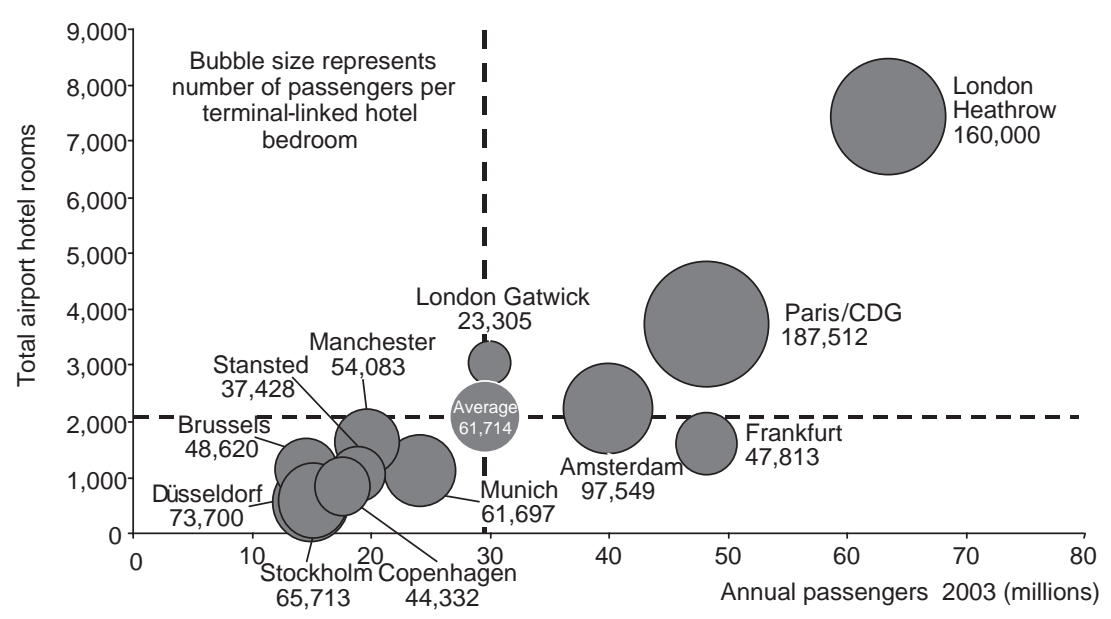

Source: $\mathrm{ACl}, \mathrm{CB}$ Richard Ellis Hotels Research

Figure 5: Airport size versus hotel supply and terminal-linked hotels 
New developments

\section{Growth of secondary airports}

per terminal-linked hotel room. The figures for Stansted include the two hotels which are due to open this year. The terminal-linked Radisson SAS with 500 bedrooms was originally planned to be 350 bedrooms with a further 150 rooms to be added later. The growth rate of Stansted Airport has beaten all expectations, however, and it was quickly decided that 500 rooms would easily be absorbed into the market.

Despite the significant hotel market already existing at Heathrow, the size of the bubble suggests that Heathrow could be undersupplied by terminal-linked hotel rooms. The development of the new Terminal 5 at Heathrow effectively creates a completely new market. The new terminal, which will open in 2008, allows BAA the opportunity to reconfigure the airport to allow for the development of the Airbus A380 'superjets' which will carry up to 650 passengers on each flight. The move of all British Airways flights to the new Terminal 5 presents a massive opportunity for the new 600-bedroom terminal-linked hotel. The ground-breaking expressions of interest in leasing and operating the hotel are testament to how the international hotel market has perceived the scale of this opportunity.

According to the analysis above, Paris Charles de Gaulle Airport would also appear to present a significant opportunity, with only 254 terminal-linked hotel rooms at the Sheraton Paris Airport Hotel. But the growth prospects for this airport are more limited than at Heathrow, and although not directly linked there are two other hotels which are well connected to the airport.

Some airports do not offer the opportunity for hotel development linked to the terminal and are missing from this picture, including Madrid, Milan, Barcelona and Paris-Orly.

\section{OPPORTUNITIES FOR THE FUTURE}

The outlook for the future of the airport hotel market appears rosy, with the continued growth of air travel forecast across Europe. Some of the smaller European airports, including Prague, Budapest and Vienna, are experiencing substantial double-digit growth rates. But it is clear from the discussions above that the opportunity for future hotel development does not necessarily arise purely from increasing passenger numbers. Further analysis is required to ascertain the types of passengers using the airport as well as the opportunity for other commercial development around the airport.

A classic example of this can be taken from the low-cost airlines and their focus on small regional airports with cheap (subsidised?) landing slots. The fact that Ryanair can pull its flights almost immediately from these airports means that hotel development in these locations may be far too risky. Similarly, airports with a high proportion of charter flights are at the mercy of the tour operator, who can increase or decrease capacity as required. This makes charter airlines uneasy bedfellows for hotels which do not have this flexibility of supply. 


\section{New concepts}

Conversely, the charter/low-cost airline industry is still growing at a significant rate. In order to minimise costs these airlines tend to occupy the most inconveniently timed take-off and landing slots that exist. Is there an opportunity for alliances between charter/lowcost airlines and, say, budget hotels at these airports to offer accommodation-flight packages?

Clearly, hoteliers will need to think more creatively in order to identify opportunities at some airports. One relatively new concept in airports is airside hotels, ie hotels for transit passengers situated within the 'duty-free' area. An excellent example of such an operation is at Singapore Changi Airport. The hotel allows transit passengers to reserve a room for as long or short a time as required, by the hour, to rest between flights and may also offer fitness facilities including swimming pools. With increasing awareness of the health risks of long-haul flights, this may become a critical requirement at major airline hubs.

Airport terminals themselves may also become increasingly competitive with airport hotels, offering a greater range of retail, restaurant, leisure, conference and meeting facilities. Airport hotels would do well to anticipate these future trends and prepare to become more competitive themselves. The benefits of connectivity are becoming obvious. 